\title{
DNA double strand break repair enzymes function at multiple steps in retroviral infection Yasuteru Sakurai ${ }^{1,2}$, Kenshi Komatsu ${ }^{3}$, Kazunaga Agematsu ${ }^{4}$ and Masao Matsuoka*1
}

\author{
Address: ${ }^{1}$ Laboratory of Virus Control, Institute for Virus Research, Kyoto University, 53 Shogoin Kawahara-cho, Sakyo-ku, Kyoto 606-8507, Japan, \\ ${ }^{2}$ Laboratory of Cell Regulation and Molecular Network, Graduate School of Biostudies, Kyoto University, Kyoto 606-8501, Japan, ${ }^{3}$ Department of \\ Genome Repair Dynamics, Radiation Biology Center, Kyoto University, Yoshidakonoe-cho, Sakyo-ku, Kyoto 606-8501, Japan and ${ }^{4}$ Department \\ of Infection and Host Defense, Graduate School of Medicine, Shinshu University, 3-1-1, Asahi, Matsumoto, Nagano 390-8621, Japan \\ Email: Yasuteru Sakurai - ysakurai@virus.kyoto-u.ac.jp; Kenshi Komatsu - komatsu@house.rbc.kyoto-u.ac.jp; \\ Kazunaga Agematsu - agemts_k@shinshu-u.ac.jp; Masao Matsuoka* - mmatsuok@virus.kyoto-u.ac.jp \\ * Corresponding author
}

Published: 15 December 2009

Retrovirology 2009, 6:114 doi:10.1186/1742-4690-6-1/4

This article is available from: http://www.retrovirology.com/content/6/l/II4

(C) 2009 Sakurai et al; licensee BioMed Central Ltd.

This is an Open Access article distributed under the terms of the Creative Commons Attribution License (http://creativecommons.org/licenses/by/2.0), which permits unrestricted use, distribution, and reproduction in any medium, provided the original work is properly cited.
Received: 9 September 2009

Accepted: 15 December 2009

\begin{abstract}
Background: DNA double strand break (DSB) repair enzymes are thought to be necessary for retroviral infection, especially for the post-integration repair and circularization of viral cDNA. However, the detailed roles of DSB repair enzymes in retroviral infection remain to be elucidated.

Results: A GFP reporter assay showed that the infectivity of an HIV-based vector decreased in ATM- and DNA-PKcs-deficient cells when compared with their complemented cells, while that of an MLV-based vector was diminished in Mrell I- and DNA-PKcs-deficient cells. By using a method based on inverse- and Alu-PCR, we analyzed sequences around 3' HIV-I integration sites in ATM, Mre I I- and NBSI- deficient cells. Increased abnormal junctions between the HIV-I provirus and the host DNA were found in these mutant cell lines compared to the complemented cell lines and control MRC5SV cells. The abnormal junctions contained two types of insertions: I) GT dinucleotides, which are normally removed by integrase during integration, and 2) inserted nucleotides of unknown origin. Artemis-deficient cells also showed such abnormalities. In Mre I Ideficient cells, part of a primer binding site sequence was also detected. The 5 ' host-virus junctions in the mutant cells also contained these types of abnormal nucleotides. Moreover, the host-virus junctions of the MLV provirus showed similar abnormalities. These findings suggest that DSB repair enzymes play roles in the 3'-processing reaction and protection of the ends of viral DNA after reverse transcription. We also identified both $5^{\prime}$ and $3^{\prime}$ junctional sequences of the same provirus by inverse PCR and found that only the $3^{\prime}$ junctions were abnormal with aberrant short repeats, indicating that the integration step was partially impaired in these cells. Furthermore, the conserved base preferences around HIV-I integration sites were partially altered in ATM-deficient cells.
\end{abstract}

Conclusions: These results suggest that DSB repair enzymes are involved in multiple steps including integration and pre-integration steps during retroviral replication. 


\section{Background}

Integration of viral DNA into the host genome is essential for retroviral replication. In this step, the integrase removes the two terminal nucleotides at each 3 ' end of the viral DNA (3'-processing) and catalyzes the joining of the processed end to the host DNA (strand transfer) [1]. Since the two ends attack the target DNA in a 5'-staggered fashion, single strand gaps between viral DNA and the target DNA are generated. Host DNA repair enzymes are thought to repair these gaps (post-integration repair). Additionally, unintegrated viral DNA is circularized to form two kinds of circular viral DNAs, 2-LTR circles and 1-LTR circles. Formation of these circular DNAs is also catalyzed by host DNA repair enzymes. Recent studies reported DNA double-strand break (DSB) repair enzymes as candidate catalysts for the post-integration repair and the circularization of viral DNA [2,3].

DSBs are the most serious damage that chromosomal DNA suffers, and must be repaired immediately and appropriately. When DSBs are generated in cellular DNA, ataxia-telangiectasia-mutated (ATM), a major molecular sensor of DSBs, directly binds to the damaged DNA and activates DSB repair pathways by phosphorylating target proteins $[4,5]$. One of the major targets is the MRN complex, which consists of Mre11, Rad50 and NBS1 [6]. This complex has recently been reported to further enhance ATM activation by recruiting ATM into the damaged site [7-9]. After detecting the damage, ATM activates two DSB repair pathways; homologous recombination (HR), and non-homologous end joining (NHEJ) [10]. In the NHEJ pathway, DNA-dependent protein kinase (DNA-PK), which consists of DNA-PK catalytic subunit (DNA-PKcs) and $\mathrm{Ku}$, binds and holds the two ends of the break together. Then ligase IV/XRCC4/XLF carries out the ligation reaction $[11,12]$. When the ends are not suitable for direct ligation, Artemis nuclease often processes the ends [13].

Retroviral transduction into mutant cells lacking DNA-PK or ligase IV was reported to induce apoptosis [14-16], suggesting that NHEJ is involved in retroviral replication. Moreover, Lau et al. showed that an ATM-specific inhibitor suppressed integration of HIV-1 [17]. These reports support the involvement of DSB repair enzymes in postintegration repair. However, in vitro experiments showed only the involvement of the components of the singlestrand break repair pathway $[18,19]$. In addition, some reports showed that DSB repair enzymes were only involved in the circularization of viral DNA $[20,21]$. However, the observation that $\mathrm{Ku}$ binds to retroviral preintegration complex (PIC) raises the possibility that DSB repair enzymes may play other roles in integration or pre-

integration steps [20]. Thus, the detailed roles of these enzymes remain to be elucidated.

We report here that defects in DSB repair enzymes enhanced the formation of abnormal junctions between retroviral DNA and the host DNA. Moreover, we observed that the base preferences around HIV-1 integration sites partially changed in ATM-deficient cells. These results indicate that DSB repair enzymes are involved in multiple steps of retroviral replication.

\section{Results}

\section{Effects of DSB repair enzymes on retroviral transduction efficiency}

Previous reports demonstrated that retroviral infectivity decreased in cells lacking DSB repair enzymes such as ATM and DNA-PKcs $[14,16,17]$. To confirm whether the enzymes affect HIV-1 infectivity, mutant cell lines and complemented cell lines were transduced with an HIVbased vector encoding a GFP reporter gene. As shown in Figure $1 \mathrm{~A}$, the transduction efficiency was impaired in the mutant cells lacking ATM compared to the complemented cells, indicating that ATM is involved in HIV-1 transduc-

$$
\text { A }
$$
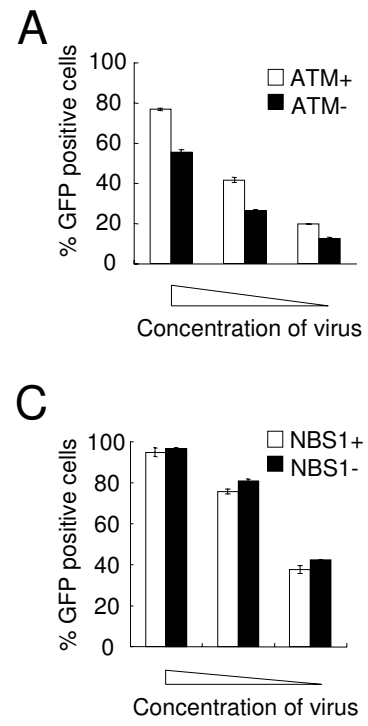

\section{Figure I}

Transduction efficiency of the HIV-based vector into cells deficient in DSB repair enzymes. (A) ATM-deficient cells and ATM-complemented cells were transduced with three different dilutions of the HIV-based vector encoding a GFP reporter. Two days postinfection, the percentage of GFP-positive cells was determined by flow cytometry. (BD) The influence of DNA-PKcs (B), NBSI (C) and Mrel I (D) on transduction efficiency of the HIV-based vector was investigated by the same method as (A). Error bars represent +/SD. 
tion. We also found that DNA-PKcs-deficient M059J cells showed a significantly lower level of transduction efficiency compared to DNA-PKcs-positive M059K cells (Figure $1 \mathrm{~B}$ ), indicating that DNA-PKcs is also required for stable transduction of HIV-1.

The influences of NBS1 and Mre11 on retroviral infectivity were controversial in previous reports $[21,22]$. In our cell lines, NBS1 and Mre11 deficiencies did not influence transduction efficiency (Figure 1C and 1D), suggesting that the MRN complex might not affect HIV-1 transduction.

We also investigated whether defects in these DSB repair enzymes affected MLV infectivity by using an MLV-based vector encoding a GFP reporter gene. As for the HIV-based vector, the infectivity of the MLV-based vector significantly decreased in DNA-PKcs-deficient cells, indicating the conserved role of DNA-PKcs in retroviral infection (Additional file S1B). Mre11-deficient cells also showed impaired MLV infectivity compared to the complemented cells (Additional file S1D). However, infectivity of MLV vector remained intact in the mutant cells lacking NBS1, which is the other component of the MRN complex (Additional file S1C). This might be due to the different extents of deficiencies of Mre11 and NBS1. In contrast to the HIV-based vector, ATM-deficient cells showed similar transduction efficiency of the MLV-based vector compared to the complemented cells (Additional file S1A). These results suggest that DSB repair enzymes are differentially required for the stable transduction of HIV-1 and MLV.

\section{Abnormal junctions between HIV-I provirus and the host DNA in ATM-, Mre I I-, NBSI- and Artemis-deficient cells} Since one of the potential targets of DNA repair enzymes is the junction between provirus and the host DNA $[18,19,23]$, we postulated that abnormal junctions would be generated in cells deficient in DNA repair enzymes. We therefore analyzed the sequences of the host-virus junctions. After amplification of integration sites by Alu PCR, we used inverse PCR to amplify the sequences around the integration sites with primers specific to LTRs and Alu repeat elements [24]. With this method, we could identify integration sites efficiently, with few non-specific amplification products.

We analyzed 216 3' junctions between HIV-1 provirus and the host DNA in a control cell line, MRC5SV, and found one abnormal junction with a single nucleotide insertion, and seven junctions with deletions in viral DNA ends (Figure 2). In mutant cells lacking DSB repair enzymes, there were more abnormal junctions with inserted nucleotides between provirus and the host DNA. There were two different groups of abnormal nucleotides. One was a GT dinucleotides (or a G mononucleotide) adjacent to the provirus that is normally removed by integrase in 3'processing. They did not originate from the host DNA. The other type of abnormal junction contained inserted nucleotides of unknown origin. The number of abnormal junctions with insertions was 1 of $216(0.5 \%)$ events in the control cells, but 8 of $161(5.0 \%)$ events in ATM-deficient cells (Figure 2 and Table 1). In ATM-complemented cells, 1 of $151(0.7 \%)$ junctions had abnormal insertions, which was a significantly lower frequency than that of ATM-deficient cells. Although GFP reporter assays showed that defect of the MRN complex did not affect HIV-1 infectivity, the junctions in the MRN complex deficient cells also had abnormal insertions: 11 of 147 (7.5\%) junctions in Mre11-deficient cells and 6 of 145 (4.1\%) junctions in NBS1-deficient cells. It is of note that some of the abnormal junctions in Mre11-deficient cells also included 2, 4, 11 , or 15 nucleotides of the primer binding site (PBS) sequences (Figure 2). In contrast, abnormal junctions with insertions were less frequent in Mre11-complemented cells (2 of 144: 1.4\%) and NBS1- complemented cells (1 of 168: $0.6 \%$ ). These results indicate that both Mre11 and NBS1 are indeed associated with HIV-1 replication. In contrast, in DNA-PKcs-deficient cells, only 3 of $153(2.0 \%)$ junctions had abnormal insertions (Additional file S2), which is not a statistically significant difference compared to control MRC5SV cells.

Abnormal junctions with insertions were also found in 10 of $136(7.4 \%)$ junctions in cells deficient in Artemis (Fig-

Table I: The number of 3' abnormal junctions of the HIV-I provirus

\begin{tabular}{|c|c|c|c|c|c|c|c|c|}
\hline & ATM(-) & ATM(+) & Mrel I(-) & Mrel I(+) & NBSI(-) & NBSI(+) & Artemis(-) & MRC5SV \\
\hline Insertions & 8 & $\mathbf{I}$ & 11 & 2 & 5 & $\mathbf{I}$ & 9 & I \\
\hline Insertions + Deletions & $\mathbf{0}$ & $\mathbf{0}$ & 0 & $\mathbf{0}$ & $\mathbf{I}$ & $\mathbf{0}$ & $\mathbf{I}$ & $\mathbf{0}$ \\
\hline Deletions & 2 & 3 & 2 & 3 & 2 & 5 & I & 7 \\
\hline Total junctions & 161 & $|5|$ & 147 & 144 & 145 & 168 & 136 & 216 \\
\hline$P$ value & $\begin{array}{c}0.012 \\
(0.0046)\end{array}$ & $(0.80)$ & $\begin{array}{c}0.023 \\
(0.00005)\end{array}$ & $(0.34)$ & $\begin{array}{c}0.035 \\
(0.013)\end{array}$ & $(0.86)$ & $(0.0003)$ & \\
\hline
\end{tabular}

The $P$ values under the columns of the deficient cell lines are for comparison of the number of junctions with only insertions or both insertions and deletions to that of the corresponding complemented cell lines. The numbers in parentheses under the table represent the $P$ values compared to the control MRC5SV cells. 


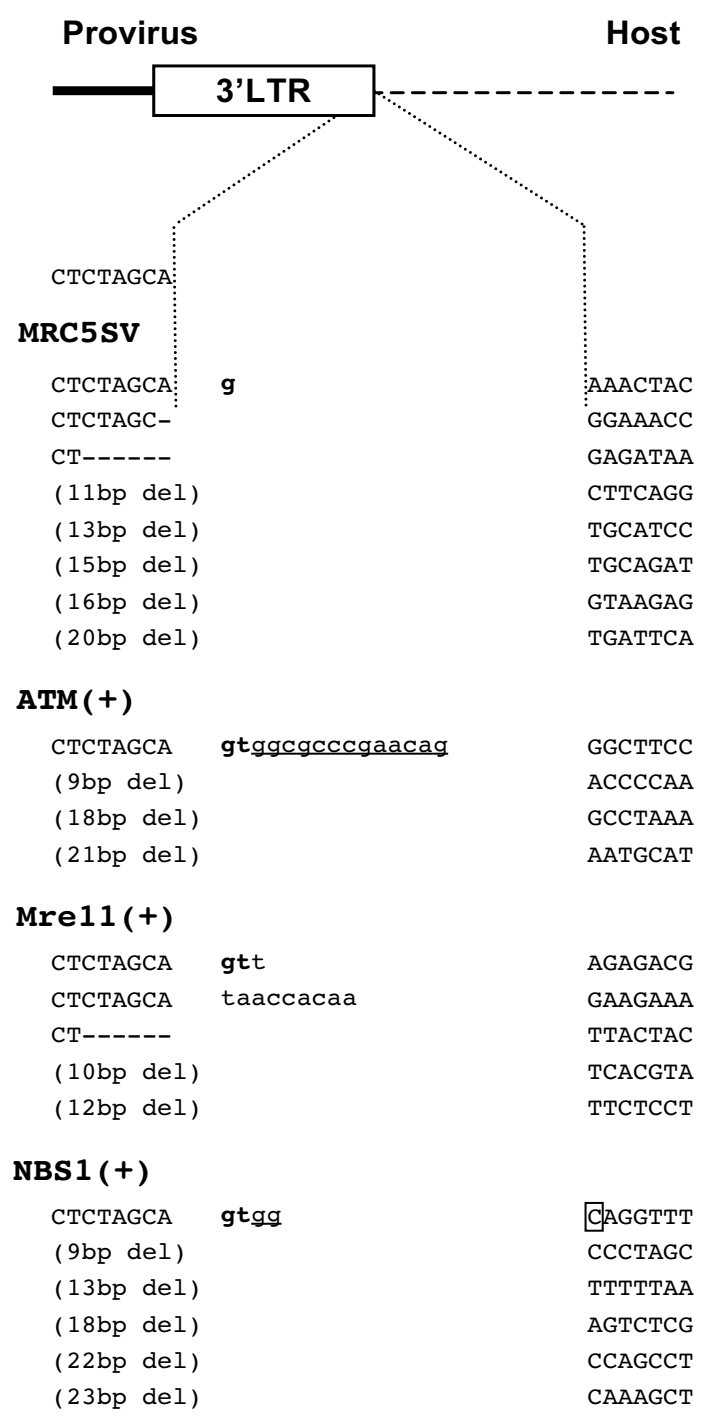

\begin{tabular}{|c|c|c|}
\hline \multicolumn{3}{|l|}{$\operatorname{ATM}(-)$} \\
\hline СТСTAGCA & g & TTCAAGA \\
\hline СТСTAGCA & g & TGCACAC \\
\hline СТCTAGCA & g & TGAGCCT \\
\hline СTCTAGCA & gt & GTGGTGG \\
\hline СTCTAGCA & gt & GGTGGGG \\
\hline СТСTAGCA & $\mathrm{cca}$ & ACACACA \\
\hline СТСTAGCA & tgaggca & CAGTGGT \\
\hline СТСTAGCA & gectgcctcggectcccaaagt & GCTGGGA \\
\hline (11bp del) & & GGTCAAA \\
\hline (13bp del) & & GGGCGGG \\
\hline
\end{tabular}

\begin{tabular}{|c|c|c|}
\hline \multicolumn{3}{|l|}{$\operatorname{Mre11}(-)$} \\
\hline СТCTAGCA & g & 四Tttagt \\
\hline СTCTAGCA & gt & CAGATTC \\
\hline СTCTAGCA & gt & CCCACTG \\
\hline СTCTAGCA & gttcacgcc & АТТСТСС \\
\hline СTCTAGCA & gtg & CССTCAG \\
\hline СTCTAGCA & gtgtgt & GCCACTG \\
\hline СTCTAGCA & gtgg & dCAGGTT \\
\hline СтСтAGCA & gtggcg & DAAGGCT \\
\hline СтCTAGCA & gtggcgeccgaac & AGGTGTA \\
\hline СTCTAGCA & gtggcgeccgaacaggg & AdCTCGA \\
\hline СТCTAGCA & atgacatg & TAAGAAA \\
\hline СтстА--- & & ССтАTGC \\
\hline СТ------ & & AGTATAG \\
\hline \multicolumn{3}{|l|}{ NBS1 (-) } \\
\hline СтCTAGCA & g & TGGdAAT \\
\hline СTCTAGCA & gttggtgctcca & TAAGAAA \\
\hline СTCTAGCA & atatc & TAATTCA \\
\hline СTCTAGCA & ggtgaggctcgaactcac & AACCACT \\
\hline СТСtAGCA & ctcacgcaaaatatactcccga & AAAAAGC \\
\hline СтCTAG-- & tagccc & CGCATGA \\
\hline (20bp del) & & CAAGAGA \\
\hline (50bp del) & & СТАСТAG \\
\hline
\end{tabular}

\section{Artemis (-)}

$\begin{array}{lll}\text { CTCTAGCA } & \mathbf{g} & \text { AGGGCTA } \\ \text { CTCTAGCA } & \mathbf{g} & \text { GTTAGCC } \\ \text { CTCTAGCA } & \mathbf{g t} & \text { CAGTTAA } \\ \text { CTCTAGCA } & \mathbf{g t} & \text { ATAAAGC } \\ \text { CTCTAGCA } & \mathbf{g t t} & \text { TCCCAAC } \\ \text { CTCTAGCA } & \mathbf{g t g} & \text { CCACCAC } \\ \text { CTCTAGCA } & \mathbf{g t g a a} & \text { CTCATGT } \\ \text { CTCTAGCA } & \mathbf{g t g c c a} & \text { TCCCAGG } \\ \text { CTCTAGCA } & \mathrm{c} & \text { TAACTGT } \\ (12 \mathrm{bp} \text { del) } & \text { ttttc } & \text { AGTCCTT } \\ (11 \mathrm{bp} \text { del) } & \text { GGGAGCT }\end{array}$

\section{Figure 2}

Abnormal 3' junctions of the HIV-I provirus in DSB repair enzyme deficient cells. Junctions between the 3' end of the provirus and the host DNA were analyzed in control cells, mutant cell lines, and complemented cell lines transduced with the HIV-based vector. Inserted abnormal sequences are lowercased. Abnormal nucleotides corresponding to the GT dinucleotides processed by integrase are presented in bold. Partial primer binding site (PBS) sequences are underlined. Squares indicate the location of micro-homologies to the GT dinucleotides and/or PBS. 
ure 2 and Table 1), which is a target of phosphorylation by ATM and DNA-PKcs $[25,26]$. Since Artemis-complemented cells could not be established, we could not conclude that these abnormalities observed in Artemis deficient cells were due to the deficiency of Artemis. However, the frequency was much higher than that of control MRC5SV cells $(P=0.0003)$, indicating the potential effects of Artemis on HIV-1 replication.

Some of the abnormal junctions also exhibited microhomologies in the host sequences, in which 1-4 nucleotides were identical to a part of the GT dinucleotides and/or the PBS sequence following the inserted part (Figure 2). This observation suggests that at least some proviruses with such abnormal junctions might be integrated by a recombination mechanism using these microhomologies.

\section{5 ' junctional sequences in DSB repair enzymes-deficient cells}

To investigate whether the abnormalities were common to both ends of provirus, we also analyzed the sequences of 5' junctions. The junctions between the HIV-1 5' LTR and the host DNA also exhibited similar abnormalities (Figure 3A). Abnormal nucleotides were observed in 10 of $164(6.1 \%)$ junctions in ATM-deficient cells and 13 of 134 (9.7\%) junctions in Mre11-deficient cells, compared to 2 of $178(1.1 \%)$ junctions in MRC5SV cells (Figure 3B). In 5 ' junctions, the remaining nucleotides were AC dinucleotides, which are complementary to the GT dinucleotides detected in 3' junctions. In Mre11 deficient cells, 3' polypurine tract (PPT) sequences were also identified. Thus, defects in DSB repair enzymes enhanced the abnormal joining of both ends of the HIV-1 DNA.

\section{Abnormal junctions of $M L V$ provirus in DSB repair enzyme deficient cells}

To determine whether these abnormalities are specific to HIV-1, we also analyzed sequences of the 3 ' junctions of the MLV provirus. Junctions with abnormal nucleotides increased from 5 of 228 (2.2\%) events in Mre11-complemented cells to 20 of 256 (7.8\%) events in Mre11-deficient cells (Figure 4). The abnormal junctions also included TT dinucleotides, which are usually removed by MLV integrase in 3'-processing. Taken together, these results show that defects in DSB repair enzymes increase abnormal host-virus junctions in both HIV-1 and MLV.

\section{Junctional sequences at the both ends of provirus}

To study whether both 5'- and 3'-junctions of the same provirus were abnormal, we analyzed both 5 ' and 3 ' junctional sequences of the same provirus. Since the method used in Figure 2, 3 and 4 could detect only one end of provirus, we next adopted a traditional inverse PCR method. We identified three HIV-1 proviruses with abnormal junc-

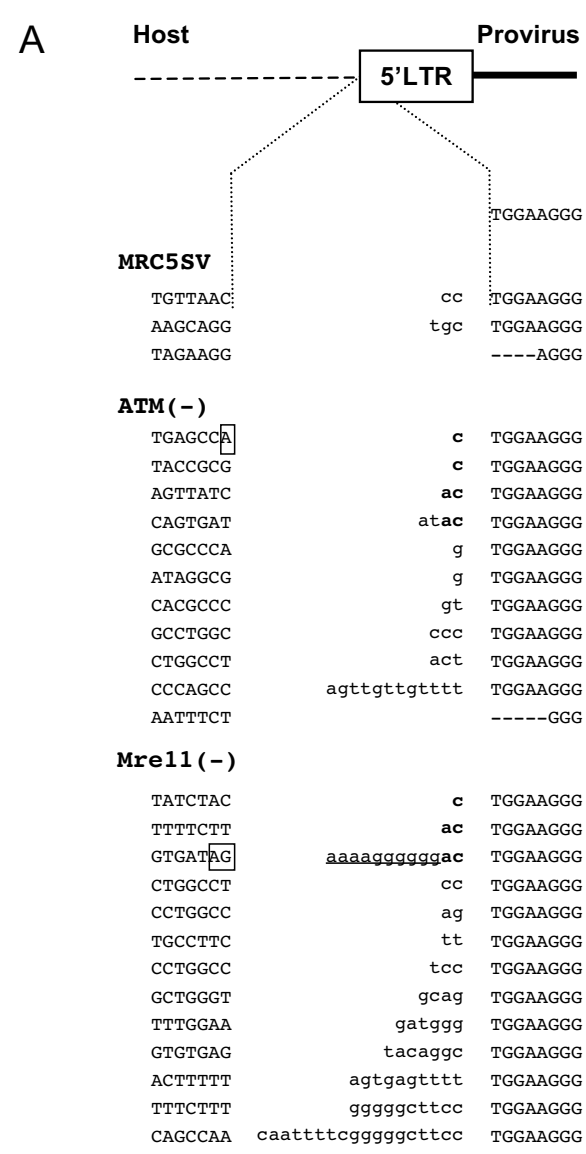

B

\begin{tabular}{cccc}
\hline & MRC5Sv & ATM(-) & Mre11(-) \\
\hline Insertions & $\mathbf{2}$ & $\mathbf{1 0}$ & $\mathbf{1 3}$ \\
Deletions & 1 & 1 & 0 \\
Total junctions & 178 & 164 & 134 \\
\hline$P$ value & & 0.013 & 0.0005
\end{tabular}

\section{Figure 3}

Abnormal 5 ' junctions of the HIV-I provirus in DSB repair enzyme deficient cells. $(A)$ Junctions between the 5 ' end of the provirus and the host DNA were analyzed in control and mutant cell lines transduced with the HIV-based vector. Inserted abnormal sequences are in lower case.

Abnormal nucleotides corresponding to the sequence (AC) complementary to the GT dinucleotides processed by integrase are presented in bold. Partial polypurine tract (PPT) sequences are underlined. Squares indicate the location of micro-homologies to the AC dinucleotides and/or PPT. (B) The number of junctions with insertions or deletions. The $P$ values under the table are for comparison of the number of junctions with insertions in each cell line to that of the control MRC5SV cells. 


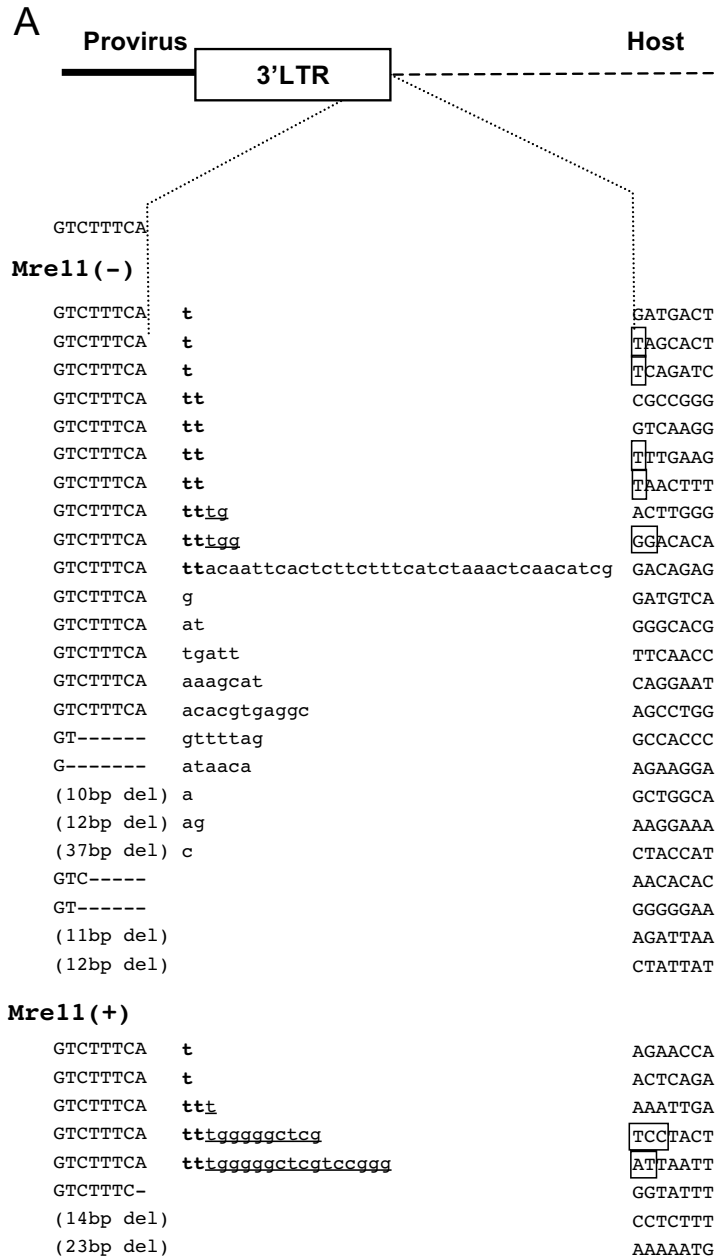

B

\begin{tabular}{ccc}
\hline & Mre11(-) & Mre11(+) \\
\hline Insertions & $\mathbf{1 5}$ & $\mathbf{5}$ \\
Insertions + Deletions & $\mathbf{5}$ & $\mathbf{0}$ \\
Deletions & 4 & 3 \\
Total junctions & 256 & 228 \\
\hline$P$ value & 0.0053 &
\end{tabular}

\section{Figure 4}

Abnormal 3' junctions of the MLV provirus in Mrel Ideficient cells. (A) Junctions were analyzed in Mrel I-deficient cells and Mrel I-complemented cells transduced with the MLV-based vector. Abnormal nucleotides corresponding to dinucleotides (TT) processed by integrase are in bold. Underlined sequences indicate partial PBSs. Squares indicate the location of micro-homologies to TT dinucleotides and/or the PBS. (B) The number of junctions with insertions or deletions. The $P$ values under the table are for comparison of the number of junctions with insertions in Mre I I-deficient cells to that of Mrel I-complemented cells. tions in Mre11-deficient cells (Figure 5). All three proviruses had the abnormal nucleotides at the 3 ' junctions. A single G was inserted in case 1, while both GT dinucletotides and part of a PBS were inserted in cases 2 and 3 . These 3' junctions also showed micro-homologies in the host sequences, confirming the abnormalities shown in Figure 2. However, the $5^{\prime}$ junctions were intact in these proviruses, indicating that these 5 ' junctions were processed by integrase as per normal. We also found that the host sequence adjacent to the provirus contained short repeats in case 1 and 2. Although all of the other proviruses had 5-bp short repeats as reported previously (data not shown), case 1 and 2 contained 3-bp and 2-bp short repeats, respectively. Case 3 lacked short repeats. These results suggest that the integration of these proviruses was catalyzed by integrase, but in abnormal ways.

\section{Altered base preference surrounding HIV-I integration sites in cells lacking ATM}

Retrovirus-specific base preferences in the immediate vicinity of integration sites have been reported [27-29]. Our findings of abnormal host-virus junctions prompted us to investigate whether deficiencies in DSB repair enzymes also influence these preference patterns. We analyzed the nucleotide frequencies for the 8 nucleotides downstream and the 4 nucleotides upstream of the $3^{\prime}$ ends of HIV-1 proviruses without insertions and/or deletions (Figure 6B). As shown in Figures 6 and 7, we calculated $P$ values at each position by $\chi^{2}$ analysis comparing the base compositions in each cell line and the average base compositions in the human genome (A:29\%, T:29\%, G:21\%, C:21\%). At the positions with $P<0.01$, the bases with high frequencies or low frequencies were focused and colored in Figure 6 and 7. Compared to the control MRC5SV cells and ATM-complemented cells, which showed a preference pattern similar to that in the previous report [28], ATM-deficient cells showed a partially altered pattern. In the position -2 , the different patterns were found in ATM-deficient cells compared to control MRC5SV cells $(P<0.0001)$ or ATM-complemented cells $\left(P<10^{-14}\right)$. Especially, ATM-deficient cells showed higher frequency of G compared to the control MRC5SV cells and the complemented cells at the position -2. Similarly, integration sites for the $5^{\prime}$ end of the provirus in ATM-deficient cells showed a changed preference pattern in position 7 compared to the control MRC5SV cells $(P<$ 0.001 ), in which ATM-deficient cells showed a higher frequency of $\mathrm{G}$ (Figure 7B). Since the 5 bp sequence (positions 1 to 5 ) is duplicated next to the $3^{\prime}$ and $5^{\prime}$ ends of the provirus as short repeats, position 7 for the 5 ' end of the provirus corresponds to position -2 for the 3 ' end of the provirus. This indicates that the analyses at both ends of the provirus showed the same change, suggesting the influence of deficiency in ATM in the position. In contrast, NBS1- and Mre11-deficient cells showed no clear change 


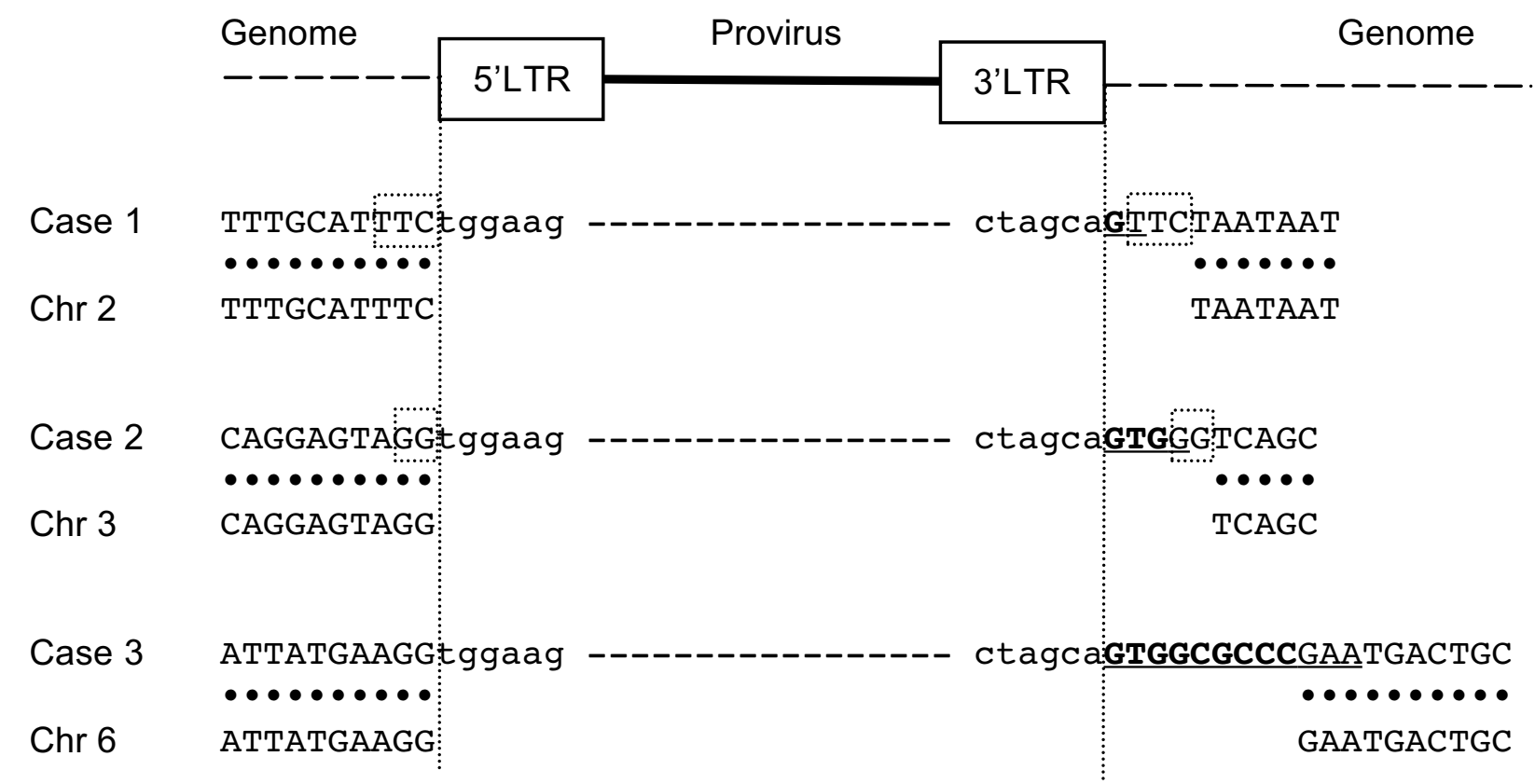

\section{Figure 5}

The 5' and 3' junctional sequences of the same HIV provirus in Mre I I-deficient cells. Junctions between both ends of HIV provirus and the host DNA were analyzed together in Mrel I-deficient cells transduced with the HIV-based vector. Three cases including abnormal junctions are shown. In each case, the integrated HIV provirus (top) and the host genome (bottom) are compared. Proviral sequences are in lower case. Inserted abnormal nucleotides are shown in bold. The GT dinucleotides and primer binding site (PBS) sequences are underlined. Squares indicate short repeats flanking the provirus.

in base preference (data not shown). Thus, deficiency in ATM partially influences the local base preference pattern surrounding HIV-1 integration sites.

\section{Effects of the MRN complex on circularization of HIV-I cDNA}

Previous reports suggested that some DSB repair enzymes were involved in the formation of 2-LTR circles and 1-LTR circles [20,21]. To investigate whether the formation of abnormal host-virus junctions links to circularization of viral cDNA, we quantified total viral cDNA, 2-LTR circles and 1-LTR circles in Mre11-deficient cells and the complemented cells. Quantitative analyses of these viral cDNAs showed that the amount of all three types of viral cDNA was similar in the deficient cells and the complemented cells (Figure 8). This suggested that deficiency in the MRN complex did not influence the formation of viral circular DNAs at least in these cell lines.

\section{Discussion}

This study revealed that deficiencies in some DSB repair enzymes caused abnormalities surrounding retroviral integration sites. Although the GFP reporter assay indicated involvement of ATM and DNA-PKcs in HIV-1 infec- tion consistent with previous reports [14,16,17], the sequence analyses of the host-virus junctions revealed that Mre1 1 and NBS1 were also involved in HIV-1 infection. In addition, both the GFP reporter assay and the sequence analysis showed the involvement of Mre 11 in MLV infection. These results suggest that DSB repair enzymes are more important in retroviral infection than previously thought.

We found two kinds of abnormal junctions in ATM-, Mre11-, NBS1- and Artemis-deficient cells. One contained remnant dinucleotides, which are normally removed from the ends of viral DNA. These were identical to nucleotides processed in 3'-processing [30], which suggest that integrase could not completely process the terminal dinucleotides, or that the processed 3'-ends were repaired during integration. This abnormality suggests that ATM, the MRN complex and Artemis play roles in the 3'-processing activity of integrase and possibly the protection of the ends of viral DNA before strand transfer. In addition, abnormal junctions containing sequences derived from the PBS were found only in Mre11-deficient cells. As the tRNA primer is thought to be removed by the RNase $\mathrm{H}$ domain of reverse transcriptase (RT) [31,32], Mre11 may 
A

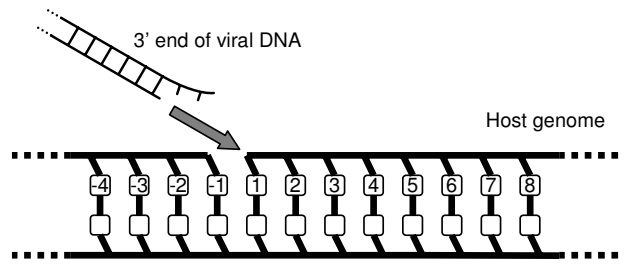

B

MRC5SV (207 sites)
\begin{tabular}{c|c|c|c|c|c|c|c|c|c|c|c|c|} 
A & -4 & -3 & -2 & -1 & 1 & 2 & 3 & 4 & 5 & 6 & 7 & \multicolumn{1}{c|}{8} \\
T & 60 & 133 & 110 & 98 & 117 & 140 & 173 & 30 & 98 & 120 & 195 \\
\hline & 103 & 165 & 93 & 78 & 33 & 138 & 107 & 78 & 88 & 68 & 105 & 58 \\
\hline G & 120 & 115 & 120 & 174 & 219 & 67 & 74 & 81 & 145 & 85 & 55 & 62 \\
\hline & 108 & 55 & 48 & 46 & 81 & 62 & 67 & 53 & 173 & 143 & 115 & 69 \\
\hline
\end{tabular}

$\operatorname{ATM}(+)$ (147 sites)

\begin{tabular}{c|c|c|c|c|c|c|c|c|c|c|c|c|c|}
\multicolumn{1}{c}{-4} & -3 & -2 & -1 & 1 & 2 & 3 & 4 & 5 & 6 & 7 & \multicolumn{1}{c|}{8} \\
\hline
\end{tabular}

ATM(-) (151 sites)

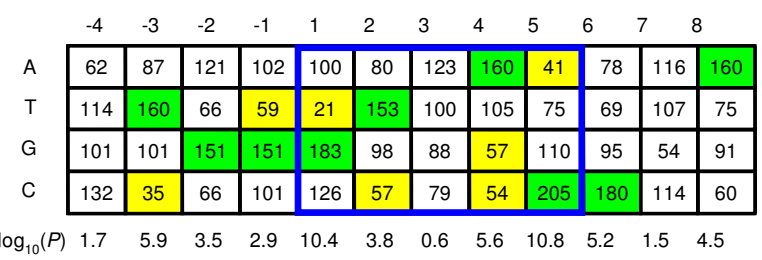

\section{Figure 6}

The local base preferences surrounding 3 ' ends of HIV-I proviruses integrated in ATM-deficient cells.

(A) A schematic figure of the strand transfer reaction of HIVI. The 3' end of viral DNA attacks the phosphodiester bond between positions $-I$ and I of the host DNA, and covalently joins to the position I nucleotide. (B) Base compositions around the integration sites in the control MRC5SV cells, ATM-complemented cells and ATM-deficient cells. The sequences represent the target DNA sequence before the viral DNA is inserted between the position I and -I. The 5 bp sequences (positions I to 5), which are duplicated next to both ends of the provirus, are boxed by blue lines. Each tabulated number represents the observed base frequency divided by the expected base frequency at each position. The expected base frequencies are average frequencies observed in human genome (A:29\%, T:29\%, G:21\%, C:21\%). The $P$ values are obtained by $\chi^{2}$ analysis comparing observed and expected base compositions at each position. At the positions with $P<0.01$, frequencies $<60 \%$ and frequencies $>$ $140 \%$ of expected frequencies are colored yellow and green, respectively. regulate RT to cleave the tRNA correctly. It is noteworthy that a part of 3' PPT sequence of HIV-1, which is a primer sequence for the synthesis of the plus strand, was found at $5^{\prime}$ junctions in Mre11 deficient cells. Inserted aberrant nucleotides of unknown origin were another junctional abnormality. Considering that one strand of viral DNA has already bound to the host DNA in the integration intermediate, it is likely that the inserted nucleotides were added at the viral DNA ends before strand transfer. It has been demonstrated that ATM and the MRN complex protect human telomeres, by capping them $[33,34]$. In addition, a report regarding telomere instability in Artemisdeficient cells suggests that Artemis also protects telomeres [35]. Given that telomeres and unintegrated retroviral DNA ends are similar, DSB repair enzymes including ATM, the MRN complex and Artemis may protect the ends of unintegrated viral DNA from aberrant nucleotide addition.

One reason for the inconsistency between the GFP reporter assay and the sequence analyses, particularly in Mre11 and NBS1, may be that the frequencies of the abnormalities at the host-virus junctions were low. Therefore, it was not detected by the GFP reporter assay. In addition, the GFP reporter assay could detect integrated provirus with abnormal junctions. Therefore, the GFP assay could not discriminate provirus with abnormal junctions from normally integrated provirus. It is possible that the integration efficiency of viral DNA with abnormal ends might be low compared with normal viral DNA, which might underestimate the frequencies of provirus with aberrant ends. Since the deficiencies of Mre11 and NBS1 in the mutant cell lines were reported to be only hypomorphic, the effects of their deficiencies are likely limited in this study [36]. However, the finding that the insertional abnormalities were more frequent in the deficient cell lines compared to the control cell lines indicates the existence of an association between retroviral infection and DSB repair enzymes including Mre11 and NBS1. This was also supported by one of the recent reports that identified host factors by genome-wide screening using an RNAi library [37]. In this report, the knockdown of Mre 11 decreased retroviral infectivity.

The identification of the abnormal junctions prompted us to investigate how proviruses with such junctions were integrated. The micro-homologies in the host sequences suggest that integrase-independent recombination is involved in this step (Figure 2, 3 and 4). However, when both $5^{\prime}$ and 3 ' junctional sequences of the same provirus were analyzed, only the 3 ' junctions of the provirus were abnormal while the 5 ' junctions were intact (Figure 5), suggesting the involvement of integrase in the establishment of these proviruses. In addition, although normal 
A

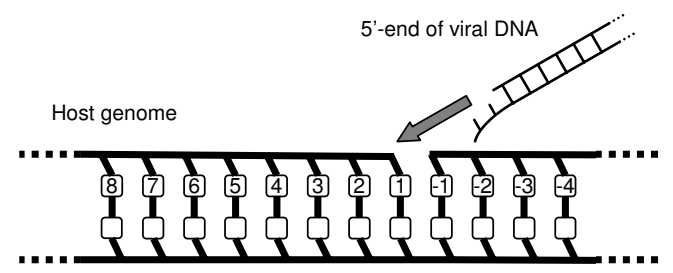

B

MRC5SV (175 sites)

\begin{tabular}{|c|c|c|c|c|c|c|c|c|c|c|c|c|}
\hline & 8 & 1 & 6 & 5 & 4 & 3 & 2 & 1 & -1 & -2 & -3 & 4 \\
\hline A & 49 & 89 & 104 & 75 & 89 & \begin{tabular}{|l|l}
120 \\
\end{tabular} & 144 & \begin{tabular}{|l|}
18 \\
\end{tabular} & 67 & 95 & 148 & 104 \\
\hline & 166 & 118 & 87 & 35 & 166 & 112 & 99 & 108 & 114 & 112 & \begin{tabular}{|l|}
73 \\
\end{tabular} & 87 \\
\hline & 125 & 122 & 147 & 199 & 57 & \begin{tabular}{|l|l|}
84 \\
\end{tabular} & 90 & 112 & 65 & 63 & 63 & 98 \\
\hline & 54 & 68 & 65 & 125 & 68 & 71 & 52 & 190 & 161 & 128 & 109 & 114 \\
\hline
\end{tabular}

$\operatorname{ATM}(-)$ (152 sites)

\begin{tabular}{|c|c|c|c|c|c|c|c|c|c|c|c|c|}
\hline & & 7 & & 5 & 4 & 3 & 2 & 1 & -1 & -2 & 3 & 4 \\
\hline A & & 104 & 113 & 75 & 84 & 100 & 132 & \begin{tabular}{|l|}
25 \\
\end{tabular} & 64 & 100 & 159 & 104 \\
\hline & 157 & 93 & 91 & 27 & 170 & 116 & 91 & 100 & 98 & 109 & 82 & 102 \\
\hline $\mathrm{G}$ & 78 & 150 & 119 & 216 & 60 & 72 & 88 & 119 & 88 & 50 & 47 & 110 \\
\hline$c$ & 75 & 53 & 75 & 119 & 66 & 107 & 81 & 185 & $\overline{166}$ & 138 & 97 & 81 \\
\hline
\end{tabular}

Figure 7

The local base preferences surrounding 5 ' ends of HIV-I proviruses integrated in ATM-deficient cells.

(A) A schematic figure of the strand transfer reaction of HIVI. The 5 ' end of viral DNA attacks the phosphodiester bond between positions - I and I of the host DNA, and covalently joins to the position I nucleotide. (B) Base compositions around the integration sites in the control MRC5SV cells and ATM-deficient cells. The sequences represent the target DNA sequence before the viral DNA is inserted between the position I and $-I$. The 5 bp sequences (positions I to 5 ), which are duplicated next to both ends of the provirus, are boxed by blue lines. Each tabulated number represents the observed base frequency divided by the expected base frequency at each position. The expected base frequencies are average frequencies observed in the human genome (A:29\%, $\mathrm{G}: 21 \%, \mathrm{C}: 21 \%$ ). The $\mathrm{P}$ values are obtained by $\chi^{2}$ analysis comparing observed and expected base compositions at each position. At the positions with $P<0.0$ I, frequencies $<60 \%$ and frequencies $>140 \%$ of expected frequencies are colored yellow and green, respectively.

HIV-1 integration generates 5-bp short repeats flanking the provirus, the abnormal proviruses lacked short repeat or had aberrant (2- or 3-bp) short repeats. These findings suggest that these proviruses were established by impaired activity of integrase.

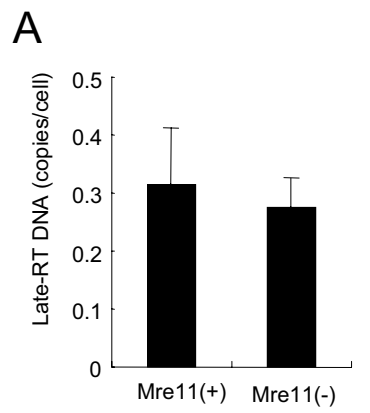

B

C
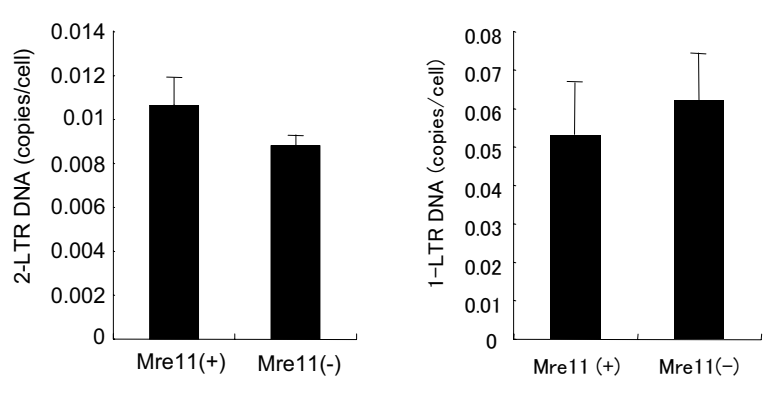

Figure 8

Quantification of viral cDNA in Mre I I-deficient cells and the complemented cells. Mrel I-deficient and complemented cells were transduced with the HIV-based vector, and the total DNA was extracted. By fluorescent-monitored quantitative PCR, total viral DNA (A), 2-LTR circles (B) and I-LTR circles (C) were quantified. Error bars represent +/SD.

There are inconsistencies in previous reports regarding the roles of DNA repair enzymes in retroviral replication [3842]. This is partly because almost all of these studies were based on measuring the retroviral infectivity or apoptosis by retroviral transduction as was done in Figure 1 and S1. Such assays largely depend on the extent of deficiencies or the expression levels of the complemented proteins. The situation is further complicated by the fact that complete deletion of some DSB repair enzymes such as Mre11 and NBS1 is lethal, and there are only hypomorphic mutant cell lines [36]. In some reports, suppressed expression of LEDGF/p75, which is a critical host factor of HIV-1 replication, had no or only modest effect on HIV-1 infectivity $[43,44]$. However, biochemical assays and sequence analyses in the same cell lines in other studies revealed a strong association of LEDGF/p75 with HIV-1 replication, suggesting that the quantitative assays could not detect all abnormalities [45-47]. Indeed, our sequence analyses revealed abnormalities undetected by the GFP reporter assay in Mre11- and NBS1- deficient cells. These results 
show the importance of qualitative assays to evaluate the involvement of host factors including DSB repair enzymes in retroviral replication.

Our sequence analyses also showed that deficiencies of DSB repair enzymes influenced HIV-1 integration site selection (Figure 6 and 7). In a recent and substantial effort to understand the mechanism of retroviral integration site selection, Holman et al. demonstrated virus-specific base preferences around retroviral integration sites by analyzing massive numbers of integration sites [28]. Our data showing partially altered patterns in ATM-deficient cells reveal that the preference pattern of HIV-1 is marginally influenced by ATM. Interestingly, a lack of ATM caused the appearance of a new base preference. As the new preference may limit the selection of a target DNA sequence, the appearance of the new preference is consistent with decreased HIV-1 infectivity in ATM-deficient cells.

Besides post-integration repair and circularization of viral cDNA, we propose additional possible roles for DSB repair enzymes. Given that Ku was reported to bind to retroviral PICs $[20,22]$, DSB repair enzymes investigated in this study may also bind to PICs and directly regulate their activities. Although further studies are necessary to validate our models regarding the roles of DSB repair enzymes, this study suggests that DSB repair enzymes are involved in retroviral replication in more ways than previously thought. This study sheds light on novel links between DSB repair enzymes and retrovirus, and raises new questions about the detailed mechanism by which DSB repair enzymes control retroviral replication.

\section{Conclusions}

This study showed aberrant sequences surrounding retroviral integration sites in DSB repair enzyme deficient cells; increased abnormal nucleotides at the host-virus junctions and partially altered base preferences surrounding integration sites. These results suggest that DSB repair enzymes are involved in both retroviral integration and pre-integration steps.

\section{Methods \\ Cell lines}

293T cells and MRC5SV cells, an SV40-transformed human fibroblast line, were cultured in Dulbecco's modified Eagle's medium (DMEM) and were supplemented with $10 \%$ fetal bovine serum, $2 \mathrm{mM}$ L-glutamine, $100 \mathrm{U} /$ $\mathrm{ml}$ penicillin, and $50 \mu \mathrm{g} / \mathrm{ml}$ streptomycin. Adenovirustransformed Artemis-deficient cells originated from RSSCID patients and were cultured in DMEM [48]. ATMdeficient and ATM-complemented cells were established by transfecting empty vector and ATM expression vector, respectively, into an A-T cell line, AT5BIVA, as described previously [49], and cultured in DMEM containing 200 $\mu \mathrm{g} / \mathrm{ml}$ hygromycin B (Calbiochem, San Diego, CA). NBS1-deficient and NBS1-complemented cells were established by transfecting empty vector and NBS1 expression vector, respectively, into an NBS cell line, GM7166VA7, as described previously [50], and cultured in DMEM containing $500 \mu \mathrm{g} / \mathrm{ml}$ G418 (Nacalai tesque, Kyoto, Japan). Mre11-deficient cells were established by transforming an ATLD2 cell line, D6809 (a generous gift from Dr. P. Concannon), by SV40, and the cells were cultured in DMEM. To obtain Mre11-complemented cells, Mre11-deficient cells were transfected with the Mre11 expression vector pCMV-Tag-Mre11, which was created by cloning Mre 11 cDNA between the EcoRI and ApaI sites of pCMV-Tag 2B (Clontech, Mountain View, CA), and the cells were cultured in DMEM containing $500 \mu \mathrm{g} / \mathrm{ml} \mathrm{G} 418$. For all experiments, we used antibiotic-free medium before $24 \mathrm{~h}$ of experiments.

\section{Production of viral vectors}

An HIV-based vector encoding a green fluorescent protein (GFP) reporter was produced as follows. 293T cells were transfected by TransFectin (Bio-Rad, Hercules, CA) with the pCSII-EF-MCS-IRES-hrGFP transfer vector [51], the pCMV- $\Delta 8 / 9$ packaging vector, and pcDNA-VSVG envelope coding vector (generous gift from Dr H Miyoshi, RIKEN, Tsukuba, Japan). Two days after transfection, the supernatant was harvested, passed through a $0.45-\mu \mathrm{m}$ pore-size filter, and then subjected to centrifugation at $4{ }^{\circ} \mathrm{C}$ and $75,000 \times g$ for $2 \mathrm{~h}$ to concentrate the virus. The virus-containing pellet was dissolved in DMEM.

To produce an MLV-based vector encoding a GFP reporter, the transfer vector $\mathrm{pDON}$-AI-2-IRES-hrGFP was created by excising IRES-hrGFP from pCSII-EF- MCS-IRES-hrGFP via BamHI/HpaI digestion and inserting the DNA into the corresponding site of pDON-AI-2 (Takara Bio, Ohtsu, Japan). GP293 cells, containing a plasmid expressing MLV gag and pol genes, were transfected with pDON-AI-2-IREShrGFP and pcDNA-VSVG. 2 days after transfection, supernatant was harvested, and virus was concentrated.

The titer of these vectors was determined using 293T cells, and scoring of transduction was performed by flow cytometry.

An HIV-based vector encoding a neomycin resistance gene was produced by transfecting the pCMV- $\Delta 8 / 9$ packaging vector, pcDNA-VSVG envelope coding vector, and CSIICMV-IRES $\mathrm{NeO}^{\mathrm{r}}$, which was constructed by inserting IRES and a neomycin resistance gene into CSII-CMV-MCS (a generous gift from Dr H Miyoshi, RIKEN, Tsukuba, Japan). 


\section{Single round transduction assay}

The mutant cell lines and the complemented cell lines were transduced with various dilutions of the HIV GFP vector or the MLV GFP vector in the presence of $8 \mu \mathrm{g} / \mathrm{ml}$ of polybrene (Sigma, St Louis, MO) for $12 \mathrm{~h}$ before changing the medium. The infected cells were harvested two days post-infection and analyzed by flow cytometry to determine the percentage of GFP-expressing cells in each sample.

\section{Cloning of retroviral integration sites}

For cloning of retroviral integration sites by the Alu-PCRbased method, cells transduced with the HIV-based vector for 2 days were collected and the genomic DNA was obtained by standard phenol-chloroform methods with proteinase $\mathrm{K}$ treatment. 3' junctional sequences of HIV were amplified by 1 st long PCR using a primer (HIV3-1) specific to the U5 region in the HIV LTR and a primer (Alu-1) specific to the Alu repeat sequence. The amplification products were blunted using T4 DNA Polymerase (TOYOBO, Osaka, Japan), phosphorylated using T4 Polynucleotide Kinase (TOYOBO), and circularized and/or concatemerized using T4 DNA Ligase (TOYOBO). The ligation products were amplified by 2 nd long PCR using a primer (HIV3-2) specific to the U5 region in the HIV LTR and a primer (HIV3-3) spanning the junctions generated by ligation. Similarly, 5' junctional sequences of HIV were amplified by 1st PCR using a primer (HIV5-1) specific to the $\mathrm{U} 3$ region in the HIV LTR and a primer (Alu-2) specific to the Alu repeat sequence, and 2nd PCR using a primer (HIV5-2) specific to the U3 region in the HIV LTR and a primer (HIV5-3) spanning the junctions generated by ligation. 3' junctional sequences of MLV were amplified by 1 st PCR using a primer (MLV3-1) specific to the U5 region in the MLV LTR and a primer (Alu-1) specific to Alu repeat sequence, and 2nd PCR using a primer (MLV3-2) specific to the $U 5$ region in the MLV LTR and a primer (MLV3-3) spanning the junctions generated by ligation. The 2nd PCR products were cloned into the pGEM-T Easy Vector (Invitrogen, Carlsbad, CA), which allows for isolation of individual clones.

For cloning of integration sites including 5 ' and 3 ' ends of the same provirus, Mre11-deficient cells were transduced by the HIV-based vector encoding a neomycin resistance gene and cultured in DMEM containing $500 \mu \mathrm{g} / \mathrm{ml} \mathrm{G418}$ for a month. After DNA extraction, the genomic DNA was digested with EcoRI, circularized using T4 DNA Ligase, and digested with NotI. Then, both of the junctional sequences of HIV provirus were amplified by 1st long PCR using a primer (HIV-U5) specific to the U5 region in the HIV LTR and a primer (HIV5-1) that was previously described and 2nd long PCR using another primer (HIV31) that was previously described and a primer (HIV-U3) specific to the $\mathrm{U} 3$ region in the HIV LTR. The 2nd PCR products were cloned into the pGEM-T Easy Vector.

The sequences of the primers used in these assays are described in Additional file 3.

\section{Sequence analysis of retroviral integration sites}

Sequencing was performed using the Big Dye Terminator (version 3.1) cycle sequencing kit and an ABI3130 autosequencer (both from Applied Biosystems, Foster City, CA). The BLAT program http://genome.ucsc.edu, hosted at the University of California, Santa Cruz, was used to search each integration clone against the March 2006 freeze of the human genome. Low-quality sequences and sequences with $<20$ base pairs (bp) were discarded.

\section{Quantification of HIV-I cDNA}

HIV-1 cDNA was quantified by fluorescent-monitored quantitative PCR (Taqman) with an ABI Prism 7700 sequence detection system (Applied Biosystems) essentially as described [24]. Cells were infected with the HIVbased vector and the total DNA was extracted with DNAzol (Invitrogen) after $12 \mathrm{~h}$ or $24 \mathrm{~h}$ for analysis of total cDNA or 2-LTR and 1-LTR circles, respectively. Sequences of primers and probes are as follows; total cDNA forward, late RT F: 5'-TGTGTGCCCGTCTGTTGTGT-3'; total cDNA reverse, late RT R: 5'-GAGTCCTGCGTCGAGAGAGC-3'; total cDNA probe, LRT-P: 5'-(FAM)-CAGTGGCGCCCGAACAGGGA-(TAMRA)-3'; 2-LTR circle forward, 2-LTR F: 5'-AACTAGGGAACCCACTGCTTAAG-3'; 2-LTR reverse, 2-LTR-R: 5'-TCCACAGATCAAGGATATCTTGTC-3'; 2-LTR probe, MH603: 5'-(FAM)-ACACTACTTGAAGCACTCAAGGCAAGCTTT-(TAMRA)-3'; 1 LTR circle forward, 1-LTR F: 5'-CACACCTCAGGTACCTTTAAGA-3'; 1-LTR reverse, 1-LTR-R: 5'-GCGCTTCAGCAAGCCGAGTCCT-3'; 1-LTR probe, MH603: 5'-(FAM)ACACTACTTGAAGCACTCAAGGCAAGCTTT-(TAMRA)-

3'. Under our PCR conditions with 1-LTR-F and 1-LTR-R primers, 1-LTR circle products ( $660 \mathrm{bp})$ were preferentially amplified compared with 2-LTR circle products ( 1170 bp), as described previously [52]. This was verified by checking the specific amplicon generated by standard PCR with the same conditions. For standard curves, we constructed control plasmids by PCR amplification from the total DNA extracts using the same primers as fluorescent-monitored quantitative PCR and cloning the products into the pGEM-T Easy Vector.

\section{Competing interests}

The authors declare that they have no competing interests.

\section{Authors' contributions}

YS and MM designed and performed research; KK and KA contributed new reagents/analytic tools; YS, KK, and MM analyzed data; YS and MM wrote the paper. 


\section{Additional material}

\section{Additional file 1 \\ Figure S1. Transduction efficiency of an MLV-based vector into cells defi- cient in DSB repair enzymes. Description: The transduction efficiency of the MLV-based vector was drastically decreased in DNA-PKcs-deficient cells and decreased in Mre11-deficient cells, but not altered in ATM- and NBS1-deficient cells. (A) ATM-deficient cells and ATM-complemented cells were transduced with the MLV-based vector encoding a GFP reporter. 2 days postinfection, the percentage of GFP-positive cells was determined by flow cytometry. (B-D) The influence of DNA-PKcs (B), NBS1 (C) and Mre11 (D) on transduction efficiency of the MLV-based vector was inves- tigated by the same method as in (A). Error bars represent $+/-S D$. Click here for file \\ [http://www.biomedcentral.com/content/supplementary/1742- 4690-6-114-S1.PDF]}

\section{Additional file 2}

Figure S2. Abnormal 3' junctions of the HIV-1 provirus in DNA-PKcsdeficient cells. Description: (A) Junctions between the 3' end of the provirus and the host DNA were analyzed in DNA-PKcs-deficient cells transduced with an HIV-based vector. Inserted abnormal sequences are in lower case. Abnormal nucleotides corresponding to the GT dinucleotides processed by integrase are presented in bold. (B) The number of junctions with insertions and/or deletions. The $\mathrm{P}$ values under the table are for comparison of the number of junctions with only insertions or both insertions and deletions to that of MRC5SV cells in Table 1.

Click here for file

[http://www.biomedcentral.com/content/supplementary/17424690-6-114-S2.PDF]

\section{Additional file 3}

Table S1. Primers for the sequence analyses around retroviral integration sites.

Click here for file

[http://www.biomedcentral.com/content/supplementary/17424690-6-114-S3.PPT]

\section{Acknowledgements}

We thank Dr. P. Concannon (University of Virginia, VA, USA) for providing Mre I I-deficient cells, Dr H. Miyoshi (RIKEN, Tsukuba, Japan) for providing plasmids required for production of viral vectors, M. Shimada (Kyoto University, Kyoto, Japan) and M. Shirakawa (Kyoto University, Kyoto, Japan) for valuable advice, and the members of Matsuoka laboratory for helpful discussions.

This work was supported by Research Fellowships of the Japan Society for the Promotion of Science for Young Scientists.

\section{References}

I. Delelis O, Carayon K, Saib A, Deprez E, Mouscadet JF: Integrase and integration: biochemical activities of HIV-I integrase. Retrovirology 2008, 5: II4.

2. Skalka AM, Katz RA: Retroviral DNA integration and the DNA damage response. Cell Death Differ 2005, I 2(SuppI I):97I-978.

3. Smith JA, Daniel R: Following the path of the virus: the exploitation of host DNA repair mechanisms by retroviruses. ACS Chem Biol 2006, I:217-226.

4. Lavin MF, Kozlov S: ATM activation and DNA damage response. Cell Cycle 2007, 6:931-942.
5. Kurz EU, Lees-Miller SP: DNA damage-induced activation of ATM and ATM-dependent signaling pathways. DNA Repair (Amst) 2004, 3:889-900.

6. Zhao S, Weng YC, Yuan SS, Lin YT, Hsu HC, Lin SC, Gerbino E, Song MH, Zdzienicka MZ, Gatti RA, Shay JW, Ziv Y, Shiloh Y, Lee EY: Functional link between ataxia-telangiectasia and Nijmegen breakage syndrome gene products. Nature 2000, 405:473-477.

7. Uziel T, Lerenthal Y, Moyal L, Andegeko Y, Mittelman L, Shiloh Y: Requirement of the MRN complex for ATM activation by DNA damage. EMBO J 2003, 22:56|2-562।.

8. Lee JH, Paull TT: ATM activation by DNA double-strand breaks through the Mrell-Rad50-NbsI complex. Science 2005, 308:55I-554

9. Dupre A, Boyer-Chatenet L, Gautier J: Two-step activation of ATM by DNA and the Mre I I-Rad50-Nbs I complex. Nat Struct Mol Biol 2006, 13:45I-457.

10. O'Driscoll M, Jeggo PA: The role of double-strand break repair - insights from human genetics. Nat Rev Genet 2006, 7:45-54.

II. Lees-Miller SP, Meek K: Repair of DNA double strand breaks by non-homologous end joining. Biochimie 2003, 85: | |6I-I I73.

12. Sekiguchi JM, Ferguson DO: DNA double-strand break repair: a relentless hunt uncovers new prey. Cell 2006, I 24:260-262.

13. Ma Y, Pannicke U, Schwarz K, Lieber MR: Hairpin opening and overhang processing by an Artemis/DNA-dependent protein kinase complex in nonhomologous end joining and $V(D) J$ recombination. Cell 2002, 108:781-794.

14. Daniel R, Katz RA, Skalka AM: A role for DNA-PK in retroviral DNA integration. Science 1999, 284:644-647.

I5. Jeanson L, Subra F, Vaganay S, Hervy M, Marangoni E, Bourhis J, Mouscadet JF: Effect of Ku80 depletion on the preintegrative steps of HIV-I replication in human cells. Virology 2002, 300: $100-108$.

16. Daniel R, Greger JG, Katz RA, Taganov KD, Wu X, Kappes JC, Skalka AM: Evidence that stable retroviral transduction and cell survival following DNA integration depend on components of the nonhomologous end joining repair pathway. J Virol 2004, 78:8573-858I.

17. Lau A, Swinbank KM, Ahmed PS, Taylor DL, Jackson SP, Smith GC, O'Connor MJ: Suppression of HIV-I infection by a small molecule inhibitor of the ATM kinase. Nat Cell Biol 2005, 7:493-500.

18. Brin E, Yi J, Skalka AM, Leis J: Modeling the late steps in HIV-I retroviral integrase-catalyzed DNA integration. J Biol Chem 2000, 275:39287-39295.

19. Yoder KE, Bushman FD: Repair of gaps in retroviral DNA integration intermediates. J Virol 2000, 74: III91-II 200.

20. Li L, Olvera JM, Yoder KE, Mitchell RS, Butler SL, Lieber M, Martin SL, Bushman FD: Role of the non-homologous DNA end joining pathway in the early steps of retroviral infection. EMBO J 200I, 20:3272-328I.

2I. Kilzer JM, Stracker T, Beitzel B, Meek K, Weitzman M, Bushman FD: Roles of host cell factors in circularization of retroviral dna. Virology 2003, 3 I 4:460-467.

22. Smith JA, Wang FX, Zhang H, Wu KJ, Williams KJ, Daniel R: Evidence that the Nijmegen breakage syndrome protein, an early sensor of double-strand DNA breaks (DSB), is involved in HIV-I post-integration repair by recruiting the ataxia telangiectasia-mutated kinase in a process similar to, but distinct from, cellular DSB repair. Virol J 2008, 5: II.

23. Taganov K, Daniel R, Katz RA, Favorova O, Skalka AM: Characterization of retrovirus-host DNA junctions in cells deficient in nonhomologous-end joining. J Virol 200I, 75:9549-9552.

24. Butler SL, Hansen MS, Bushman FD: A quantitative assay for HIV DNA integration in vivo. Nat Med 200I, 7:63I-634.

25. Ma Y, Pannicke U, Lu H, Niewolik D, Schwarz K, Lieber MR: The DNA-dependent protein kinase catalytic subunit phosphorylation sites in human Artemis. I Biol Chem 2005, 280:33839-33846.

26. Chen L, Morio T, Minegishi Y, Nakada S, Nagasawa M, Komatsu K, Chessa L, Villa A, Lecis D, Delia D, Mizutani S: Ataxia-telangiectasia-mutated dependent phosphorylation of Artemis in response to DNA damage. Cancer Sci 2005, 96: | 34-| |4|.

27. Carteau S, Hoffmann C, Bushman F: Chromosome structure and human immunodeficiency virus type I cDNA integration: centromeric alphoid repeats are a disfavored target. J Virol 1998, 72:4005-40I4.

28. Holman AG, Coffin JM: Symmetrical base preferences surrounding HIV-I, avian sarcoma/leukosis virus, and murine 
leukemia virus integration sites. Proc Natl Acad Sci USA 2005, 102:6103-6107.

29. Derse D, Crise B, Li Y, Princler G, Lum N, Stewart C, McGrath CF, Hughes $\mathrm{SH}$, Munroe DJ, Wu X: Human T-cell leukemia virus type I integration target sites in the human genome: comparison with those of other retroviruses. J Virol 2007, $81: 673|-674|$.

30. Sherman PA, Fyfe JA: Human immunodeficiency virus integration protein expressed in Escherichia coli possesses selective DNA cleaving activity. Proc Nat/ Acad Sci USA 1990, 87:5 I I 9-5 I 23.

31. Pullen KA, Ishimoto LK, Champoux J]: Incomplete removal of the RNA primer for minus-strand DNA synthesis by human immunodeficiency virus type I reverse transcriptase. J Virol 1992, 66:367-373.

32. Smith JS, Roth MJ: Specificity of human immunodeficiency virus- $I$ reverse transcriptase-associated ribonuclease $H$ in removal of the minus-strand primer, tRNA(Lys3). J Biol Chem 1992, 267:|1507|-I5079.

33. Maser RS, DePinho RA: Telomeres and the DNA damage response: why the fox is guarding the henhouse. DNA Repair (Amst) 2004, 3:979-988.

34. Cenci G, Ciapponi L, Gatti M: The mechanism of telomere protection: a comparison between Drosophila and humans. Chromosoma 2005, II 4: I35- I 45.

35. Rooney S, Alt FW, Lombard D, Whitlow S, Eckersdorff M, Fleming J, Fugmann S, Ferguson DO, Schatz DG, Sekiguchi J: Defective DNA repair and increased genomic instability in Artemis-deficient murine cells. J Exp Med 2003, 197:553-565.

36. Stracker TH, Theunissen JW, Morales M, Petrini JH: The Mre I I complex and the metabolism of chromosome breaks: the importance of communicating and holding things together. DNA Repair (Amst) 2004, 3:845-854.

37. Konig R, Zhou Y, Elleder D, Diamond TL, Bonamy GM, Irelan JT, Chiang CY, Tu BP, De Jesus PD, Lilley CE, Seidel S, Opaluch AM, Caldwell JS, Weitzman MD, Kuhen KL, Bandyopadhyay S, Ideker T, Orth AP, Miraglia LJ, Bushman FD, Young JA, Chanda SK: Global analysis of host-pathogen interactions that regulate early-stage HIV-I replication. Cell 2008, 135:49-60.

38. Baekelandt V, Claeys A, Cherepanov P, De Clercq E, De Strooper B, Nuttin B, Debyser Z: DNA-Dependent protein kinase is not required for efficient lentivirus integration. J Virol 2000, 74: | | 278-| | 285.

39. Daniel R, Katz RA, Merkel G, Hittle JC, Yen TJ, Skalka AM: Wortmannin potentiates integrase-mediated killing of lymphocytes and reduces the efficiency of stable transduction by retroviruses. Mol Cell Biol 200I, 21: I I64-I I 72.

40. Daniel R, Kao G, Taganov K, Greger JG, Favorova O, Merkel G, Yen T], Katz RA, Skalka AM: Evidence that the retroviral DNA integration process triggers an ATR-dependent DNA damage response. Proc Natl Acad Sci USA 2003, 100:4778-4783.

41. Dehart JL, Andersen JL, Zimmerman ES, Ardon O, An DS, Blackett J, Kim B, Planelles $V$ : The ataxia telangiectasia-mutated and Rad3-related protein is dispensable for retroviral integration. J Virol 2005, 79: I389-1396.

42. Ariumi $Y$, Turelli $P$, Masutani M, Trono D: DNA damage sensors ATM, ATR, DNA-PKcs, and PARP-I are dispensable for human immunodeficiency virus type I integration. J Virol 2005, 79:2973-2978.

43. Llano M, Saenz DT, Meehan A, Wongthida P, Peretz M, Walker WH, Teo W, Poeschla EM: An essential role for LEDGF/p75 in HIV integration. Science 2006, 314:46|-464.

44. Zielske SP, Stevenson M: Modest but reproducible inhibition of human immunodeficiency virus type $I$ infection in macrophages following LEDGFp75 silencing. I Virol 2006, 80:7275-7280.

45. Llano M, Vanegas M, Fregoso O, Saenz D, Chung S, Peretz M, Poeschla EM: LEDGF/p75 determines cellular trafficking of diverse lentiviral but not murine oncoretroviral integrase proteins and is a component of functional lentiviral preintegration complexes. J Virol 2004, 78:9524-9537.

46. Ciuffi A, Llano M, Poeschla E, Hoffmann C, Leipzig J, Shinn P, Ecker JR, Bushman F: A role for LEDGF/p75 in targeting HIV DNA integration. Nat Med 2005, I I: I287-I 289.

47. Vandegraaff N, Devroe E, Turlure F, Silver PA, Engelman A: Biochemical and genetic analyses of integrase-interacting proteins lens epithelium-derived growth factor (LEDGF)/p75 and hepatoma-derived growth factor related protein 2 (HRP2) in preintegration complex function and HIV-I replication. Virology 2006, 346:4I5-426.

48. Kobayashi N, Agematsu K, Sugita K, Sako M, Nonoyama S, Yachie A Kumaki S, Tsuchiya S, Ochs HD, Sugita K, Fukushima Y, Komiyama A: Novel Artemis gene mutations of radiosensitive severe combined immunodeficiency in Japanese families. Hum Genet 2003, I I 2:348-352.

49. Sakamoto $S$, lijima $K$, Mochizuki D, Nakamura K, Teshigawara $K$, Kobayashi J, Matsuura S, Tauchi H, Komatsu K: Homologous recombination repair is regulated by domains at the $\mathrm{N}$ - and C-terminus of NBSI and is dissociated with ATM functions. Oncogene 2007, 26:6002-6009.

50. Takai K, Sakamoto S, Sakai T, Yasunaga J, Komatsu K, Matsuoka M: A Potential Link between Alternative Splicing of the NBSI Gene and DNA Damage/Environmental Stress. Radiat Res 2008, 170:33-40

5I. Kuwata H, Watanabe Y, Miyoshi H, Yamamoto M, Kaisho T, Takeda $\mathrm{K}$, Akira S: IL-10-inducible Bcl-3 negatively regulates LPSinduced TNF-alpha production in macrophages. Blood 2003, 102:4123-4I29.

52. Jacque JM, Stevenson M: The inner-nuclear-envelope protein emerin regulates HIV-I infectivity. Nature 2006, 44I:64I-645.
Publish with Bio Med Central and every scientist can read your work free of charge

"BioMed Central will be the most significant development for disseminating the results of biomedical research in our lifetime. "

Sir Paul Nurse, Cancer Research UK

Your research papers will be:

- available free of charge to the entire biomedical community

- peer reviewed and published immediately upon acceptance

- cited in PubMed and archived on PubMed Central

- yours - you keep the copyright

Submit your manuscript here:

http://www.biomedcentral.com/info/publishing_adv.asp 